\title{
Effect of Nano Filler on Conductivity in PEO-PMMA-LiClO Polymer Electrolyte
}

\author{
Shazia Farheen ${ }^{1}$ and R. D. Mathad ${ }^{2}$ \\ ${ }^{1}$ Research Scholar, ${ }^{2}$ Professor in Physics \\ Department of Post Graduate Studies and Research in Physics, Gulbarga \\ University, Gulbarga, India \\ uniirdm@rediffmail.com /shazfarheen@gmail.com
}

\begin{abstract}
The electrical conductivity of PEO-PMMA-LiClO4 polymer blend with different concentrations of TiO2 as a nano filler has been studied. The polymer blend electrolyte was prepared in the form of thin films using solution casting technique. The blend was characterized by Fourier Transform Infrared Spectroscopy (FTIR) and Scanning Electron Microscopy (SEM). The electrical properties of the blend electrolyte were investigated by complex impedance spectroscopy with varying frequencies.
\end{abstract}

Key words: Conductivity, Nano-filler, Polymer electrolytes

\section{Introduction}

Solid Polymer Electrolytes (SPE) has attracted attention since more than three decades due to their practical applications as well as for fundamental knowledge [1-5]. SPE offers many advantages, such as high durability, high flexibility and low reactivity towards the electrodes. These eliminate the problems of corrosive solvent leakage and harmful gas for above ambient temperature operations and reduce packaging cost as well as improve selflife of the lithium metal electrodes [6-7]. Several researchers have investigated a host of polymers e.g. poly (ethylene oxide-PEO), poly (methyl methacrylate-PMMA), poly (vinyl chloride-PVC) and poly (vinyl acetate- PVA) etc. In this the PEO has drawn keen interest due to its good salvation power having single helical structure which supports fast ionic conduction; but their practical applications are limited as PEO exhibits relatively high crystalline portion at ambient temperature due to its particular structure showing low ionic conductivity. To overcome this limitation, one of the approaches used is the polymer blending method. Therefore, PEO is blended with PMMA and additions of nano filler in order to improve the ionic conductivity. In the present study, a novel PEO-PMMA$\mathrm{LiClO}_{4}-\mathrm{TiO}_{2}$ blend has been developed in which Titanium dioxide $\left(\mathrm{TiO}_{2}\right)$ is used as nano filler.

\section{Experimental Method}

PEO and PMMA where purchased from Aldrich. The polymers were dried in vacuum for $24 \mathrm{hrs}$ keeping in desiccators. Lithium per chlorate ( $\mathrm{LiClO} 4)$ with purity $99.9 \%$ was supplied by Aldrich and dried under vacuum oven at $80{ }^{\circ} \mathrm{C}$ for $24 \mathrm{hrs}$. The composition of PEO/PMMA blend was 70/30 wt $\%, \mathrm{LiClO}_{4}(5 \mathrm{wt} \%)$ and $\mathrm{TiO}_{2}$ was added to this blend at different weight percentages viz 1, 2, 3, 4, and 5. Mixtures were prepared by dissolving three components separately in tetrahydrofuran (THF) and stirred for 12 hrs by using magnetic stirrer. PEO/PMMA and LIClO4 stirred for $12 \mathrm{hrs}$ separately at room temperature and $\mathrm{LiclO}_{4}$ then both the solutions were stirred for $24 \mathrm{hrs}$ and poured in a Teflon Petri dish. The sample was removed at room temperature after 24 hrs. For complete removal of solvent the samples were vacuum dried at $50{ }^{\circ} \mathrm{C}$ for another $12 \mathrm{hrs}$. 


\section{Result and Discussion}

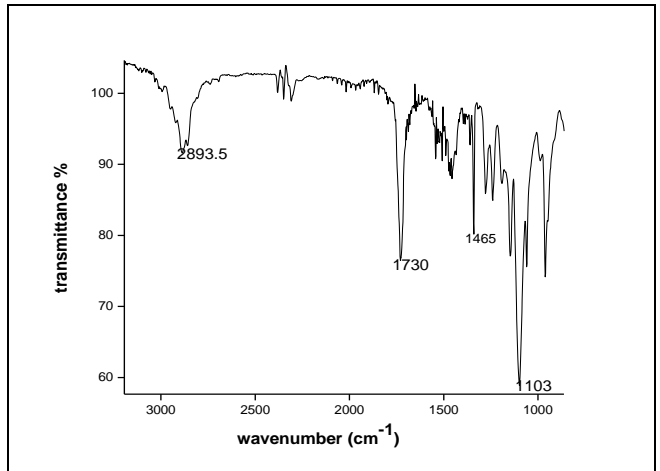

Figure 1. (a) FT-IR Spectra of PPLi Polymer Film

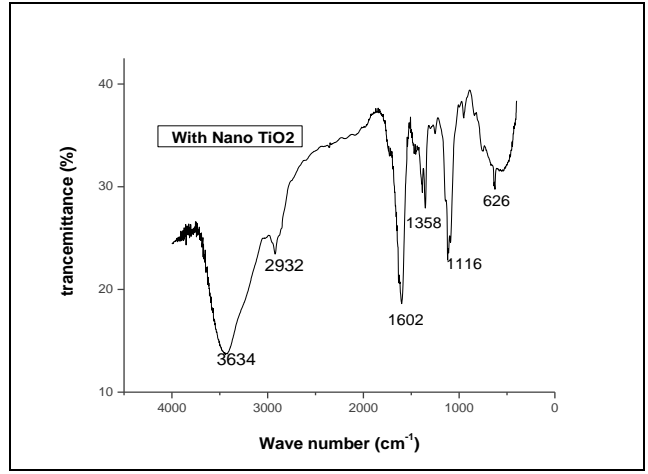

Figure 1. (b) FT-IR Spectra of $\mathrm{PPLiTiO}_{2}$ Polymer Film with $\mathrm{Nano}^{\mathrm{TiO}_{2}}$

FTIR is a useful technique to characterize the organic, inorganic and composite materials [8]. Figure 1(a) - (b) shows FT-IR spectra of Polyethylene oxide with $\mathrm{LiClO}_{4}$ (PPLi) and (PPLiTiO ${ }_{2}$ polymer films. PPLi polymer film shows IR bands at2893, 2994, $2874,2694,1730,1465,811,750$. The vibration band at 750 and $811 \mathrm{~cm}^{-1}$ is attributed to $\mathrm{CH}$ vibration of PMMA and PEO respectively. The vibrational peak at $1731 \mathrm{~cm}^{-1}$ due to the $\mathrm{C}=\mathrm{O}$ stretching of PMMA $[9,10]$ is observed to shift at $1722 \mathrm{~cm}^{-1}$. In $\mathrm{PPLiTiO}_{2}$ polymer electrolyte film, where the nano- filler is added, the peaks of IR spectrum is found to be quite broadened as compared to that of PPLi polymer electrolyte. The vibration peaks at 1602,1358 and $2932 \mathrm{~cm}^{-1}$ remain at same position but with decreased peak intensity. Hence, the above IR analysis confirms that the nano-filler $\mathrm{TiO}_{2}$ helps in enhancing the amorphous nature with flexible polymer chains.

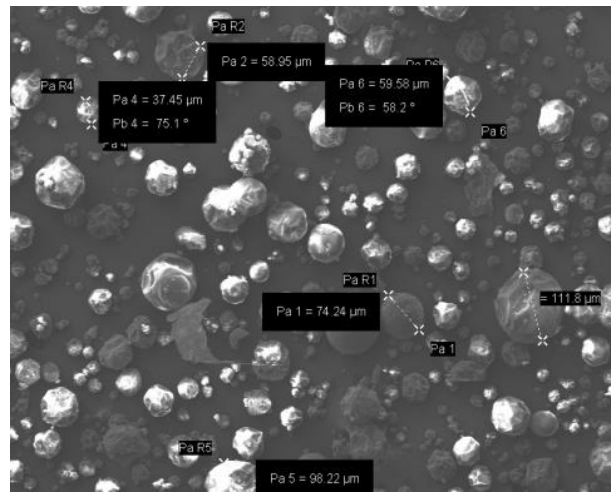

Figure 2. (a): SEM Image of the PPLi polymer Film

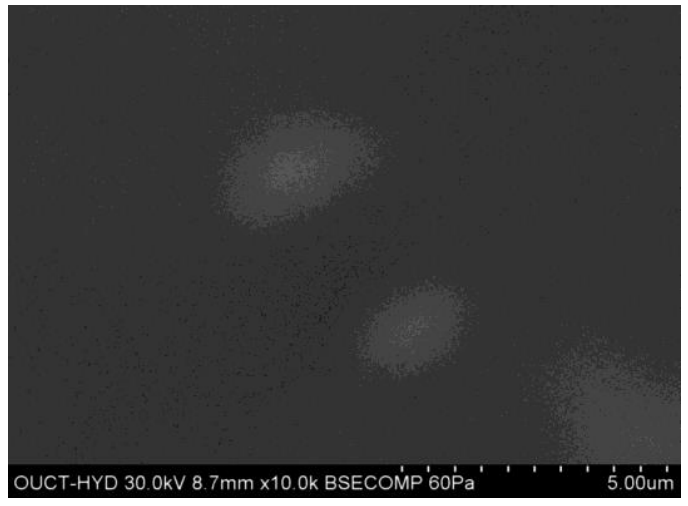

Figure 2. (b): SEM Image of the PPLi with $\mathrm{Nano}^{\mathrm{TiO}}{ }_{2}$

\section{Morphological Study}

The SEM images of the polymer films are depicted in Figure 2(a) and (b). The micrograph shows with the addition of nano-filler, the surface shows a uniformly distributed area. The above micro-structural observation is in good agreement with FT-IR result which have indicated an enhancement in the amorphous phase with the addition of nano-filler [1]. 


\section{Dielectric Studies}

The dielectric function has been observed as a function of frequency. AC conductivity $\left(\sigma_{\mathrm{ac}}\right)$ has been evaluated from dielectric data in accordance with the relation.

$$
\sigma=\omega \varepsilon_{0} \varepsilon^{\prime} \tan \delta
$$

Where $\omega$ is $2 \pi \mathrm{f}$ ( $\mathrm{f}$ is frequency), $\varepsilon_{0}$ is the permittivity of the vacuum and dielectric constant or relative permittivity.

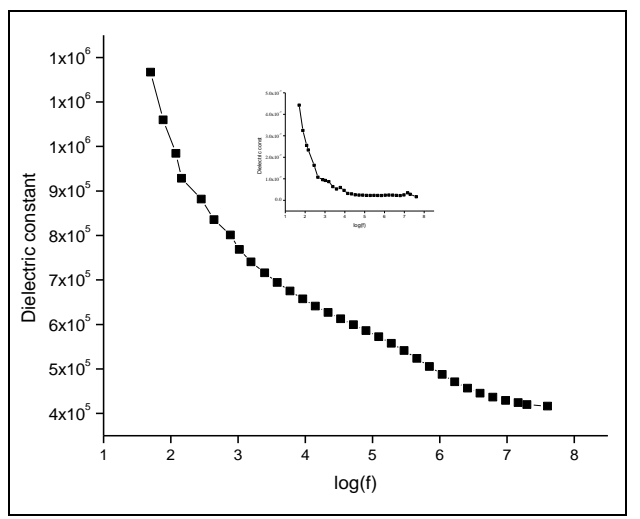

Figure 3. (a) Dielectric const of PPLi and $\mathrm{PPLiTiO}_{2}$

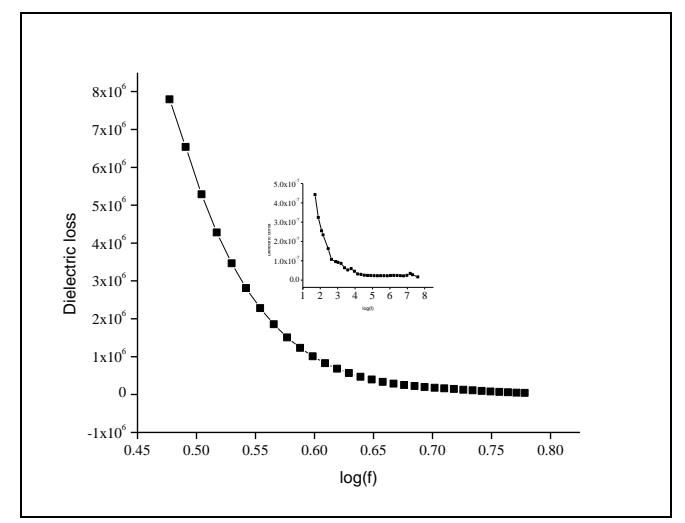

Figure 3. (b) Dielectric loss of PPLi and $\mathrm{PPLiTiO}_{2}$

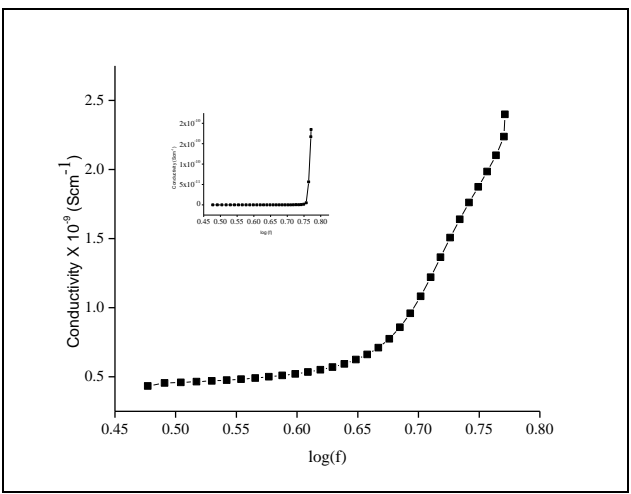

Figure 3. (c) Conductivity PPLi and $\mathrm{PPLiTiO}_{2}$

Figure 3(a) - (b) shows that there is a significant increase in $\varepsilon^{\prime}$ and $\varepsilon^{\prime \prime}$ values due to the incorporation of nano filler. The high value of $\varepsilon^{\prime}$ and $\varepsilon^{\prime \prime}$ towards low frequency attributing to the free charge build up at the interface between the polymer film and electrode. Figure 3(c) shows the conductivity decreases with lowering in frequency, which is because at lower frequencies, more and more charge accumulation occurs at the interface between electrode electrolytes causing a drop in conductivity at low frequencies due to slower or longer time scale for ionic motion to occur. The enhancement in the conductivity is explained in terms of higher dissociation of salt, due to ion-filler interaction, causing higher number of free charge carriers.

\section{Conclusion}

Polymer electrolyte films were prepared and characterized by FTIR, ac impedance, and SEM analysis. In the FTIR spectra shift in peaks and appearance of new peaks confirmed the complexation of the constituents. SEM images are good agreement with the FTIR results. The conductivity of the films has been increased by addition of nanofiller. 


\section{Acknowledgement}

The author would like to thank for the needful help received while doing experiment from Prof. AmbikaPrasad, dept of material science Gulbarga University Gulbarga. Thanks is also due, to UGC for the financial support obtained during the research work.

\section{References}

[1] J. E. Bauerle, "Study of Solid Electrolyte Polarization by a Complex Admittance Method", Journal of Physics and Chemistry of Solids, vol. 30, no. 12, (1969), pp. 2657-2670.

[2] P. V. Wright, "Polymer Electrolytes-The Early Days", Electrochimica Acta, vol. 43, no. 10-11, (1998), pp. 1137- 1143.

[3] V. D. Noto, S. Lavina, G. A. Giffin and E. Negro, "Polymer Electrolytes: Present, Past and Future", Electrochimica Acta, vol. 57, (2011), pp. 4-13.

[4] J. Evans and C. A. Vincent, "Electrochemical Measure-ment of Transference Numbers in Polymer Electrolytes", Polymer, vol. 28, no. 13, (1987), pp. 2324-2328.

[5] H. Block and A. M. North, "Dielectric Relaxation in Polymer Solutions", Advances in Molecular Relaxation Processes, vol. 1, no. 4, (1970), pp. 309-374.

[6] K. Hanai, M. Ueno, N. Imanishi, A. Hirano, O. Yamamoto and Y. Takeda, J Power Sources, doi:10.1016/j.jpowsour.2010.10.079, (2010).

[7] H. Zhang, P. Maitra and S. L. Wunder, Solid State Ionics, vol. 178, (2008), pp. 1975-1983.

[8] D. K. Pradhan, R. N. P. Choudhary, B. K. Samantaray, A. K. Thakur and R. S. Katiyar, "Effect of Montmorillonite Filler on Structural and Electrical Properties of Polymer Nanocompsite Electrolytes", Ionics, vol. 15, no. 3, (2009), pp. 345-352.

[9] S. A. M. Noor, A. Ahmad, I. A. Talib and M. Y. A. Rah-man, "Morphology, Chemical Interaction and Conductivity of a PEO- ENR50 Based on Solid Polymer Electro-lytes", Ionics, vol. 16, no. 2, (2010), pp. 161-170.

[10] S. Rajendran, V. S. Bama and M. R. Prabhu, "Effect of Lithium Salt Concentration in PVAc-PMMA Based Gel Polymer Electrolytes", Ionics, vol. 16, no. 1, (2010), pp. 27-32.

[11] P. Sharma, D. Kumar Kanchan1 and N. Gondaliya, "Effect of Nano-Filler on Structural and Ionic Transport Properties of Plasticized Polymer Electrolyte", Scientific research, vol. 2, no. 1, (2012), pp 3844.

\section{Authors}

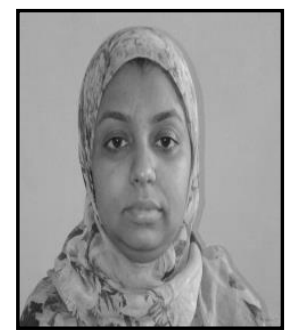

Shazia Farheen, Research Scholar in Physics, Department of Post Graduate Studies and Research in Physics, Gulbarga University, Gulbarga, India. Her present area of research is Nano materials, Material Characterization and Thin films.

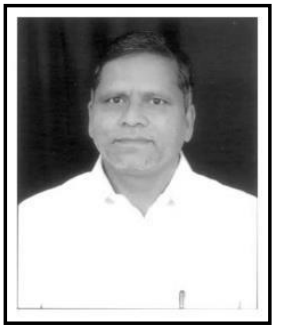

Dr R. D Mathad, earned his $\mathrm{PhD}$ in physics from Karnataka University, Karnataka, India, in 1983. He is working as Professor in Physics, Department of Post Graduate Studies and Research in Physics, Gulbarga University, Karnataka, India. INSA Grants Award for research presentation in the International Conference on Biophysics. 